\title{
Distribution and efficiency of bacteriolysis in the gut of Arenicola marina and three additional deposit feeders
}

\author{
Craig J. Plante, Lawrence M. Mayer \\ The Darling Marine Center, University of Maine, Walpole, Maine 04573, USA
}

\begin{abstract}
A simple technique was developed to measure the bacteriolytic activities of the digestive fluids of the deposit-feeding polychaete Arenicola marina. Lysis of a cultured environmental isolate, incubated with extracts of gut luminal contents, was monitored spectrophotometrically. Concurrent direct counts were used to verify cell lysis. The ability of extracts from 8 longitudinal sections of the gut to lyse the bacterium was monitored. The digestive ceca, anterior stomach, and posterior stomach regions exhibited high lytic activities, whereas bacteriolytic activities in all other regions of the gut were negligible. Similarly, extracts of surface sediments and fecal castings showed negligible lytic capabilities. The sharply limited distribution of lytic activity implicates the ceca as the source of bacteriolytic agent and suggests a true plug-flow system, with little axial mixing. Questions regarding the fate of lytic agents, which disappear abruptly posterior to the stomach, remain unanswered. Localization of lysis in the gut coupled with estimates of gut residence time permit the calculation that ingested bacteria are exposed to strong lytic activity for approximately $20 \mathrm{~min}$. Incubation of in situ sediment samples with gut fluids corroborates the distributional findings of the in vitro work although the efficiency of lysis is much reduced, possibly due to exopolymer capsules and slimes of natural sedimentary bacteria. Cross-phyletic comparisons of bacteriolytic activities reveal both qualitative and quantitative differences. Much less demarcation of lytic activity is observed in the guts of a holothuroid (Caudina arenata) and a hemichordate (Stereobalanus canadensis), with a pattern more similar to that of $A$. marina observed in another polychaete, Amphitrite johnstoni. Quantitatively, the polychaetes showed higher levels of activity with rates in A. marina exceeding those of the hemichordate and holothuroid by more than 10 -fold.
\end{abstract}

KEY WORDS: Bacteriolysis - Deposit feeding $\cdot$ Sedimentary bacteria $\cdot$ Arenicola marina $\cdot$ Amphitrite johnstoni Caudina arenata Stereobalanus canadensis

\section{INTRODUCTION}

The concept of the 'microbial loop' (Azam et al. 1983) has altered long-held views of pelagic food webs and trophic transfer. Knowledge of the benthic microbial loop is more fragmentary and extrapolations from the pelagic system are dangerous. Several important differences from the water column are evident. In pelagic systems the inability of larger zooplankton, with the possible exception of tunicates (Pomeroy et al. 1984, Diebel \& Powell 1987), to effectively graze bacteria is an important constraint on the structure of the microbial loop. Benthic systems differ in that potential bacterivores include metazoans, both meio- and macrofauna, in addition to protozoans (Kemp 1990). This difference is largely because most bacteria are attached to mineral or organic particles (e.g. Dye 1983, Ellery \& Schleyer 1984). The ubiquity and abundance of deposit-feeding macrofauna, coupled with their surprisingly high rates of sediment ingestion (e.g. Taghon 1988, Wheatcroft et al. 1990), suggest an important role as grazers of bacteria.

Ingestion by deposit-feeding macrofauna has been shown to affect biomass (e.g. Moriarty et al. 1985, Plante et al. 1989), growth (Deming \& Colwell 1982, Duchene et al. 1988, Plante et al. 1989), activity (Juniper 1981, Aller \& Yingst 1985) and community composition (Dobbs \& Guckert 1988, Duchene et al. 1988) of microbes in sedimentary and detrital environments. Both experiments and field observations indi- 
cate that invertebrate ingestion can strongly influence population dymamics of ingested bacteria, either by cell destruction (e.g. Deming \& Colwell 1982, Austin \& Baker 1988, Plante et al. 1989) or by stimulation of growth (e.g. Reyes \& Tiedje 1976, Klug \& Kotarski 1980, Deming \& Colwell 1982, Plante et al. 1989). The net result, i.e. population increase or decrease, of one or both of these processes varies among ingested microbial strains (Wavre \& Brinkhurst 1971, Baker \& Bradnam 1976, Reyes \& Tiedje 1976, Dobbs \& Guckert 1988, Duchene et al. 1988, Prieur et al. 1990). Certain bacterial strains are efficiently eliminated due to gut passage whereas others simultaneously increase in number (e.g. Wavre \& Brinkhurst 1971).

The nature of the interactions between bacteria associated with sediments and detritus and the animals ingesting these microbes is certainly diverse, and generally unclear. A central question is to what extent these ingested microorganisms contribute to, or compete for, resources with the animal. This simple question, however, masks numerous complexities. Different microbial populations will interact with the host in dissimilar ways - gut passage can be either mutually beneficial or mutually detrimental, or somewhere between these extremes. Also, the nature of association, within a given population, is likely to vary spatially within the animal's gut. Additionally, the effects of gut passage can be manifested well after the parties are no longer physically associated, e.g. stimulated bacterial growth can be observed in feces (Newell 1965, Hargrave 1970, Fenchel 1972, Juniper 1981).

We have recently presented predictions of association type and bacterial distributions within the guts of detritivores (Plante et al. 1990). The models giving rise to these predictions were based on 'optimal digestion theory' (Penry \& Jumars 1986, 1987, Dade et al. 1990). Their theory adapts reactor theory, a body of theory from chemical engineering aimed at the design of chemical reactors, to analyze the process of digestion and absorption. We (Plante et al. 1990) adapted and extended this theory in order to predict type and location of animal-microbe interaction within the guts of detritivores. A crude optimal digestion model for microbes in a gut-like environment was formulated; costs and benefits of potential associations in terms of digestive model variables were then analyzed. Predictions of association type, e.g. mutualism, competition, or parasitism, and distribution of both attached and transient microbes were thus made possible. The major cost and benefit to the microbe were concluded, respectively, to be risk of enzymatic digestion and local supply of the products of animal digestion. Briefly, our analysis suggests that the midgut should be kept free of both resident and transiting bacteria via mechanical and chemical means because microbial invasion and competition in this region of absorption would be costly to the animal. Once the 'war of absorption' is over, however, hindguts and feces of detritivores are excellent environments for microbial growth - num bers and productivity of both endosymbiotic and transient bacteria should be highest here. Foregut associations might be extremely beneficial to both parties but are unlikely to arise in small animals because of the short residence times of material in their foreguts. In general, our predictions regarding site and type of association are supported by previous observations, made without benefit of theoretical guidance. However, few experimental data to more rigorously test hypotheses are yet available.

According to this model a non-resident, transiting bacterium will experience at least 2 contrasting environments and be subject to 2 distinct 'processes', digestion and regrowth. We focus in this work on the process experienced first, digestive removal. Digestion influences the bacterial communities of detritus in at least 2 direct ways: biomass is reduced and the bacterial species composition of the ingesta is altered.

The 2 specific goals of the present study are to assess the sites and strength of bacteriolysis in deposit-feeder guts. In this initial effort we focus on animals with simple tubular guts; therefore our results are unlikely to be applicable to mollusks and crustaceans. We will test whether the 'cost' of digestion to bacteria is confined to the midgut as predicted (Plante et al. 1990). Assuming plug-flow transport of gut materials, we can also calculate the length of time bacteria are exposed to lytic agents. Time is a key variable both from the animal's perspective in that it affects both the nature and amount of food digested and from the microbe's perspective in that digestive removal of bacteria appears to be directly proportional to gut residence time (Plante \& Jumars 1993). Lytic profiles may also give hints as to the source, as well as the function, of the lytic agent. Our study also compares lysis among 4 species of deposit feeders representing 3 phyla. Similarity of results will give some indication of the extent to which we can generalize to other taxa with similar feeding modes and gut morphologies.

\section{METHODS}

Specimen collection and preparation. In vitro and in vivo bacteriolytic assays were performed using gut extracts of the lugworm Arenicola marina (Polychaeta: Arenicolidae). The guts of the tentaculate polychaete Amphitrite johnstoni (Polychaeta: Terebellidae), a subsurface-feeding enteropneust, Stereobalanus canadensis (Enteropneusta: Harrimanidae), and the apodous Caudina arenata (Holothuroidea: Molpadiidae) 
have also been profiled for bacteriolytic activity to represent different modes of deposit feeding and to allow cross-phyletic comparisons. Arenicola marina and Amphitrite johnstoni were dug by shovel at low tide from the poorly-sorted sands surrounding Pratt's Island, Maine, USA in September and November of 1992, respectively. $S$. canadensis and $C$. arenata were collected from subtidal $(-20 \mathrm{~m})$ muds of the Damariscotta River estuary in mid-coastal Maine, via Van Veen grab. S. canadensis and C. arenata were collected in January and August of 1993, respectively. All animals were either dissected on site or immediately upon return to the laboratory, within $5 \mathrm{~h}$ of collection. For dissection of Arenicola marina, the body wall was cut longitudinally to reveal an intact alimentary tract from pharynx to anus, although the rectum at times could not be cleanly separated from the body wall. Coelomic fluids were then rinsed out of the body cavity with seawater and the gut was blotted dry. The contents of the pair of large ceca were collected by suspending each into a $1.5 \mathrm{ml}$ microtube, followed by puncture with small dissecting scissors. Other gut regions, the esophagus (foregut, FG), anterior stomach (midgut, MG), posterior stomach (MG), anterior intestine $(\mathrm{MG})$, posterior intestine (MG), anterior rectum (hindgut, $\mathrm{HG}$ ), and posterior rectum (HG), were opened and sampled with a small scoopula, taking care to avoid collection of animal tissue or fluids of the body cavity. These samples were placed in $1.5 \mathrm{ml}$ polypropylene tubes and frozen until further analysis. In preliminary tests, no effects of freezing on lytic activity were observed. Total (fluid plus sediment), dry sediment, and fluid (total minus sediment) weights were later obtained for normalizations.

In general, the sampling of the other 4 animals followed the procedures used for Arenicola marina. The discrete gut sections to be sampled for the other deposit feeders were determined by visual morphological distinctions of the gut and were generally fewer than those for A. marina (Fig. 1). The small size and nature of the enteropneust guts made dissection more difficult and a small degree of contamination of samples by coelomic fluid was likely. In addition, much of the trunk of these animals is regularly lost upon collection so the most posterior portions of the animals could not be sampled.

Egestion rates were estimated for Arenicola marina at the time of collection. During ebb tide, when the worms were still under approximately $0.5 \mathrm{~m}$ of water, fecal castings were gently brushed away and marked with numbered flags. After emersion, just prior to animal collection, new casts were collected by spatula for determination of dry weight. Subsequently the dry weights of the gut contents of $A$. marina could be obtained to estimate gut 'capacity'. (Gut fullness might
Arenicola marina

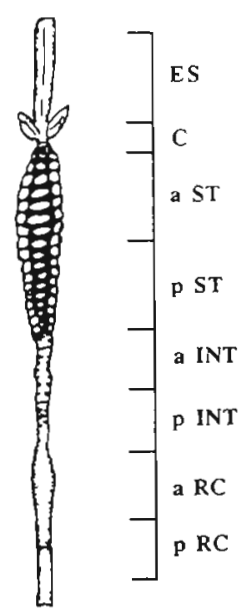

Caudina arenata

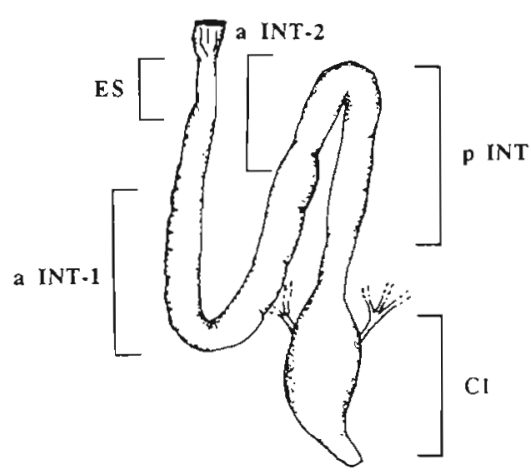

Amphitrite johnstoni

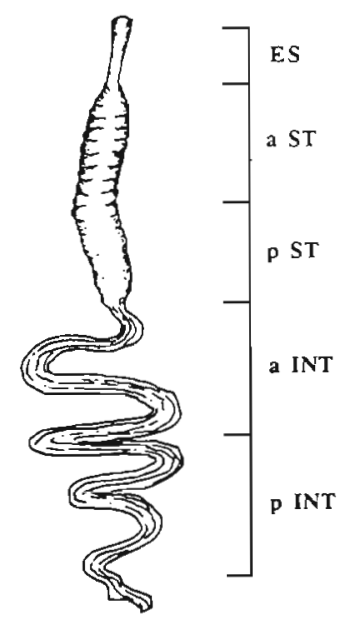

Stereobalanus canadensis

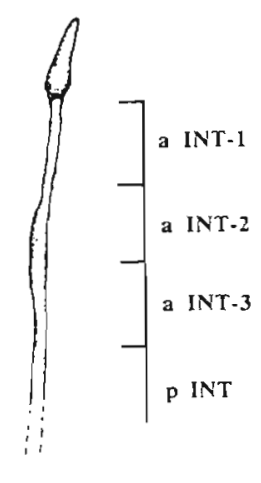

Fig. 1. Gut sections of 4 deposit feeders sampled for bacteriolytic assays. ES: esophagus; C: ceca; aST: anterior stomach; pST: posterior stomach; aINT: anterior intestine; pINT: posterior intestine; $\mathrm{aRC}$ : anterior rectum; $\mathrm{pRC}$ : posterior rectum; $\mathrm{Cl}$ : cloaca

be a more accurate term than capacity since there is no requirement that the gut be completely filled). Preliminary tests revealed that egestion rates remained constant for only about $0.5 \mathrm{~h}$ after emersion, after which drying of the sediment inhibited feeding and defecation (see also Kermack 1955), so all feces and worms were collected in this $0.5 \mathrm{~h}$ window following emersion. Gut residence time was then estimated by dividing gut capacity (weight) by egestion rate (weight time $e^{-1}$ ).

In vitro lysis assays. A traditional lysozyme assay, which follows the lysis of Micrococcus lysodeikticus (formerly M. luteus) turbidimetrically (e.g. McHenery \& Birkbeck 1982, Morsky 1983), was initially tried to quantify the bacteriolytic activity of gut juices. $M$. lysodeikticus was so resistant to lysis by gut juices, however, that turbidity loss could hardly be differenti- 
ated from that of the controls or the noise of the technique. Upon subsequent testing, numerous strains isolated from local sediments showed susceptibility to lysis under the same conditions. One such isolate, designated SS-1, was chosen to be the standard assay bacterium. This bacterium, likely a member of the Pseudomonadaceae (Table 1), was isolated from surface sediments of the Arenicola marina collection site.

SS-1 was cultured in filtered Marine Broth 2216 (Difco) overnight at $25^{\circ} \mathrm{C}$ on a shaker table. Mid- to late-log phase cells were pelleted (3000 rpm, $1200 \times$ $g, 10 \mathrm{~min}$ ), washed in $0.066 \mathrm{M}$ phosphate buffer (potassium phosphate, monobasic, $\mathrm{pH}=6.2$ ), and repelleted and resuspended in the same phosphate buffer. Preliminary tests showed that use of phosphate or tris- $\mathrm{HCl}$ buffers to wash and resuspend SS-1 enhanced bacteriolysis relative to those cells resuspended in seawater. Preliminary tests also revealed that lytic susceptibility was a function of culture age, with stationary phase cultures exhibiting markedly reduced sensitivity (unpubl. data; see also Stolp \& Starr 1965); our cultures were always pelleted at between 14 and $16 \mathrm{~h}$. Resuspensions were diluted to give an absorbance of

Table 1. Biochemical and physiological characteristics of strain SS-1, likely a member of the Pseudomonadaceae

\begin{tabular}{|lc|}
\hline Characteristic tested & Result \\
\hline Gram stain & - \\
Morphology & Rods \\
O/Fa & O \\
Anaerobic growth & - \\
Motility & + \\
Oxidase & + \\
Catalase & - \\
Production of indole & - \\
Nitrate reduction & - \\
Tryptophanase & - \\
Arginine dihydrogenase & - \\
Urease & - \\
Esculin hydrolysis & + \\
Gelatinase & + \\
Beta-galactosidase & - \\
Sodium required for growth & + \\
Utilization of D-glucose & - \\
Utilization of L-arabinose & - \\
Utilization of D-mannose & - \\
Utilization of N-acetyl-D-glucosamine & - \\
Utilization of maltose & - \\
Utilization of D-gluconate & - \\
Utilization of caprate & - \\
Utilization of adipate & - \\
Utilization of L-malate & - \\
Utilization of citrate & - \\
Utilization of phenyl-acetate & \\
a Oxidation/fermentation tests were done in & MOF \\
medium (Leifson 1963) & \\
\hline
\end{tabular}

approximately 0.600 at $450 \mathrm{~nm}$ (Spectronic 2000, Bausch \& Lomb). This absorbance $\left(A_{450}\right)$ represented a concentration of about $1 \times 10^{8} \mathrm{SS}-1$ cells ml-1.

After obtaining total (sediment + fluid) weights of samples, gut juices were extracted from gut sediment with $0.5 \mathrm{ml}$ phosphate buffer, then centrifuged $(7000$ $\mathrm{rpm}, \sim 3000 \times \mathrm{g}, 10 \mathrm{~min}$ ). Small volumes (between 10 and $100 \mu \mathrm{l}$ ) of extracted gut juices were added to $1.5 \mathrm{ml}$ SS-1 suspensions in disposable $1 \mathrm{~cm}$ polystyrene cuvette tubes. The spectrophotometer was zeroed against phosphate buffer; addition of equal volumes of phosphate buffer to the SS-1 suspensions served as controls. Lysis was followed by optical clearing, with readings taken at $0,0.25,0.50,1,2,3,5,10$, and $30 \mathrm{~min}$ after addition of gut fluid or buffer. Lytic rates were calculated using the initial linear portions of absorbance vs time plots. All lysis experiments were performed at 20 to $23^{\circ} \mathrm{C}$. The pellet from each centrifuged extract was then dried and weighed. Sample wet (i.e. fluid only) weights were obtained by subtraction so that values could be normalized to both dry and wet weight. Both normalizations were performed because, a priori, we were unsure whether lytic activity might be correlated with amount of ingesta. Samples of wet or dry weight below $7.5 \mathrm{mg}$ were not used. Obtaining a signal (i.e. decrease in absorbance) in excess of the phosphate control was difficult below this sample weight; on the other hand, a signal slightly above the control (but within the precision of the instrument) could result in anomalously high lytic activity after normalization.

From a small number of the total pool of gut sections analyzed, subsamples were fixed in $2 \%$ glutaraldehyde for microscopic enumeration. Direct counts were performed using epifluorescence microscopy. Samples were DAPI stained (20 ppm) for $6 \mathrm{~min}$ and viewed at $1000 \times$ using a Zeiss Axioskop.

Resuspension in phosphate buffer appeared to create artificial osmotic challenges for SS-1 which enhanced lysis relative to resuspension in seawater. On the other hand, the procedure outlined above undoubtedly presents an environment more dilute in gut fluids than would be experienced by sedimentary bacteria transiting the gut of Arenicola marina. To test whether SS-1 would be lysed under more realistic conditions, we washed and resuspended the bacterium in filtered seawater and added $30 \mu \mathrm{l}$ undiluted (no phosphate buffer extraction) fluids from the ceca of $A$. marina to $120 \mu$ of resuspended cells. The added gut fluids were filtered with a $0.2 \mu \mathrm{m}$ micro-spin centrifuge unit (Lida, Kenosha, WI, USA) prior to addition to avoid addition of indigenous gut flora. Subsamples were taken at 0,5 , and $60 \mathrm{~min}$ for both viable and total counts. Serial dilutions were plated in duplicate on Marine Agar 2216 plates for viable counts; direct 
counts of total bacteria were performed as described above. These experiments were performed in triplicate with seawater additions serving as controls.

Lysis of sedimentary bacteria. The digestive susceptibility of cultured bacteria in logarithmic growth may be much greater than that of natural sedimentary bacteria, most of which are attached to inorganic particles and surrounded by protective organic matrices. To assess whether extracted gut fluids would act on natural sedimentary bacteria, we added $100 \mu \mathrm{l}$ of a $50 \%$ solution (in filtered seawater) of midgut (anterior stomach) fluid to 5 samples of approximately $0.2 \mathrm{~g}$ (wet wt) of surface sediments (top $3 \mathrm{~mm}$ from the Pratt's Island site), vortexed, then removed subsamples at 5 and 60 min for viable counts.

Sediment samples with equivalent volumes of seawater or hindgut fluid served as controls. To conserve gut fluids, $t_{0}$ values were obtained with a separate treatment, with 5 separate surface sediment samples plus $100 \mu \mathrm{l}$ added seawater, rather than sampling each. of the above 3 treatments (MG, HG, and seawater additions) at $t_{0}$. Colonies were counted after a $48 \mathrm{~h}$ incubation at room temperature $\left(22\right.$ to $\left.25^{\circ} \mathrm{C}\right)$ on 2216 agar plates. At $t_{60}$, the treatments were fixed for total direct counts. Prior to filtration and DAPI staining, samples for epifluorescence enumeration were incubated for $\geq 30 \mathrm{~min}$ with $0.01 \mathrm{M}$ sodium pyrophosphate, then sonicated at $60 \mathrm{~W}$ for $30 \mathrm{~s}(3 \times 10 \mathrm{~s})$. Finally, dry weights of each sediment sample were obtained for normalization to $\mathrm{g}$ dry $\mathrm{wt}^{-1}$.

Statistics. One- or two-way ANOVAs were used to test for overall differences in means in all experiments performed. Generally, the Tukey HSD test was employed to make pairwise comparisons of means within the ANOVAs. Prior to performing these parametric statistical procedures, the assumption of homoscedasticity was checked using Bartlett's test, and data were log-transformed if necessary. All statistical tests were performed using SYSTAT (version 5.2.1) for the Macintosh computer.

\section{RESULTS}

\section{In vitro bacteriolysis}

In each lugworm assayed, the rate of lysis of bacteria varied among gut sections but consistently decreased with time as an end-point was approached (Fig. 2); the speed at which this end-point was reached was proportional to overall lytic strength, suggesting substrate
Bacteriolysis through the lugworm gut

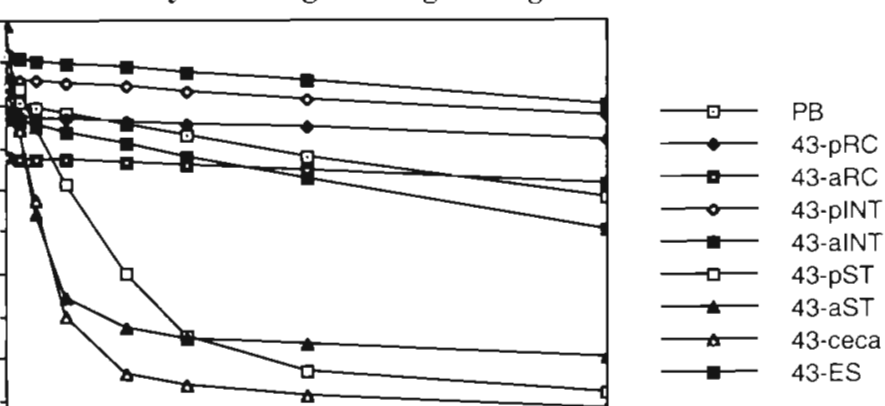

limitation in the experiments with the most active extracts. Lytic activity in the gut of Arenicola marina differed significantly among the various gut regions (1-way ANOVA, p < 0.001) (Fig. 3). Tukey's multiple comparison test clearly showed that the gut extracts separated into 2 distinct groups: the anterior and posterior stomach extracts, as well as those from the ceca, resembled each other ( $p>>0.10$ ) but differed from the phosphate buffer control and all other gut samples $(\mathrm{p}<$ $0.001)$. Activity posterior to the stomach decreased slightly with distance but the levels were statistically indistinguishable from one another ( $p>>0.10$ ). In most animals, foregut activity was not observed; however, in a few specimens weak activity was noted. Activities of

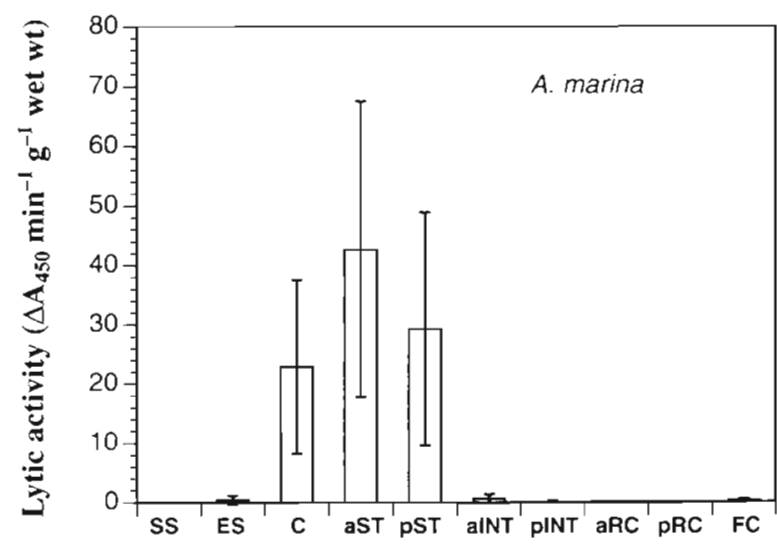

Location

Fig. 3. Arenicola marina. Mean ( $\pm 95 \% \mathrm{Cl}$ ) bacteriolytic activities of the gut regions of a lugworm (abbreviations as in Fig. 1), surface sediment (SS), and fecal coils (FC). Activities are normalized to the original fluid weight of each sample. Number of replicates for each mean ranged from 5 to 9 


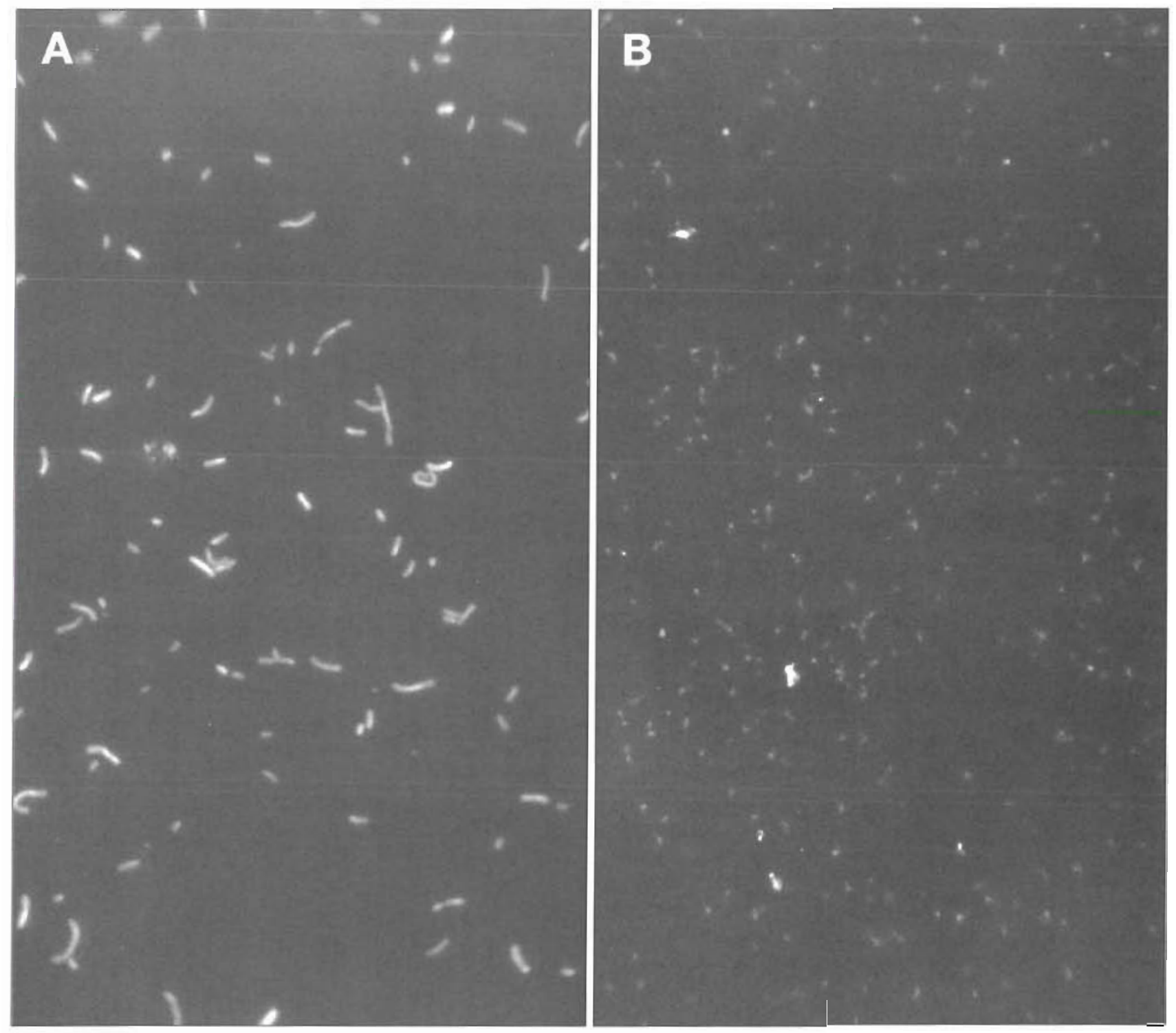

Fig. 4. Epifluorescence staining of SS-1 resuspensions (A) prior to addition of gut fluids, and (B) 5 min after midgut-fluid incubation. $1000 x$

surface sediment, fecal, and coelomic fluid extracts could not be distinguished from controls (ANOVA, $p$ $\gg 0.10)$. A slight amount of optical clearing was observed with the phosphate buffer alone (Fig. 2).

The mean gut residence time of Arenicola marina in September was $1.09 \pm 0.67 \mathrm{~h}(\mathrm{~m}=10)$. On average, the length of the lytic portion of the gut (stomach) was $30 \%( \pm 4 \%, \mathrm{n}=8)$ of the total gut length. Assuming plug-flow, ingested bacteria therefore spent approximately 20 min in the lytic portion of the gut.

Direct counts showed that cell lysis was coincident with optical clearing. Significant reductions in number were observed relative to phosphate buffer controls (2-way ANOVA, $p<0.001)$ and with respect to time ( $p$ $=0.002$ ). Qualitative changes in the staining intensity and cell integrity of SS-1 upon exposure to midgut fluids made counts more subjective with time (Fig. 4). Addition of undiluted cecal fluid to SS-1 resuspended in seawater resulted in a large and rapid loss of cells. A significant treatment effect was observed (2-way ANOVA, $p<0.001)$. Time was also significant for the gut-fluid treatment $(p<0.001)$ but not for the controls $(p>0.10)$. Cell number was reduced by $93 \%$ and $96 \%$ by 5 and $60 \mathrm{~min}$, respectively, as compared with $t_{0}$. The reduction from $t_{5}$ to $t_{60}$ was not significant ( $p>0.10$ ). Qualitatively, cell integrity and staining intensity decreased with time in a fashion similar to that noted for phosphate-buffer-resuspended SS-1 cells (see Fig. 4). No loss was observed over 5 or $60 \mathrm{~min}$ in the controls ( $p \gg 0.10$ for both times). 
The decline in colony-forming units (CFUs) was even more dramatic with addition of cecal juice; numbers at both 5 and 60 min were at least 4 orders of magnitude lower than either initial numbers or controls (2-way ANOVA; $p<0.001$ ). Controls showed no significant numerical changes through time ( $p>0.10)$.

\section{Lysis of sedimentary bacteria}

A highly significant overall treatment effect (1-way ANOVA, $p<0.001$ ) was seen among bacterial numbers in sediments incubated for 60 min in seawater, midgut and hindgut fluids, and initial numbers ( $t_{0}$ treatment). The addition of midgut fluids to surface sediments resulted in a marginally significant (Tukey's test, $\mathrm{p}=$ 0.063 ; Fisher's LSD, $p=0.014$ ) decrease in total bacterial numbers over a $60 \mathrm{~min}$ incubation (Fig. 5a), although the decrease of $45 \%$ is much smaller than the reduction in numbers of the pure culture of SS-1 observed with added gut fluids. The controls, surface sediments incubated with seawater or hindgut fluids, did not exhibit significant numerical changes (Fig. 5a; $\mathrm{p}>0.10$ ).

Similar trends were obtained for viable counts on Marine Agar 2216 plates, with significant numerical losses $(p<0.001)$ observed with midgut fluid exposure but not in controls (Fig. 5b). The reduction in viability (or ability to culture on 2216 agar medium) was proportionally much higher, at $>99 \%$, than was the reduction in total cell counts (at $45 \%$ ). The high variances in the hindgut-fluid incubations are due to anomalously high CFUs in 1 replicate (with high counts at both $t_{5}$ and $\left.t_{60}\right)$; if these values are deleted, both means and variance are nearly identical to those for the seawater controls.

\section{Cross-phyletic comparisons}

Qualitatively, the gut fluids among the 4 deposit feeders differed most obviously in fluid content and color. Arenicola marina represented one extreme; the midgut of this deposit feeder was more fluid-rich than the ingested sediments or other parts of the lugworm gut. Additionally, by far the greatest relative increase in fluid content was observed in A. marina as compared to the other animals studied (Table 2). Yellow color and an apparent soapiness not found in ingested fluids indicated that this excess fluid was secreted by the animal. Caudina arenata and Stereobalanus canadensis demonstrated the other extreme in that gut contents visually resembled ingested sediments, with no obvious soapiness, color change or changes in fluid content. Amphitrite johnstoni was more like A. marina
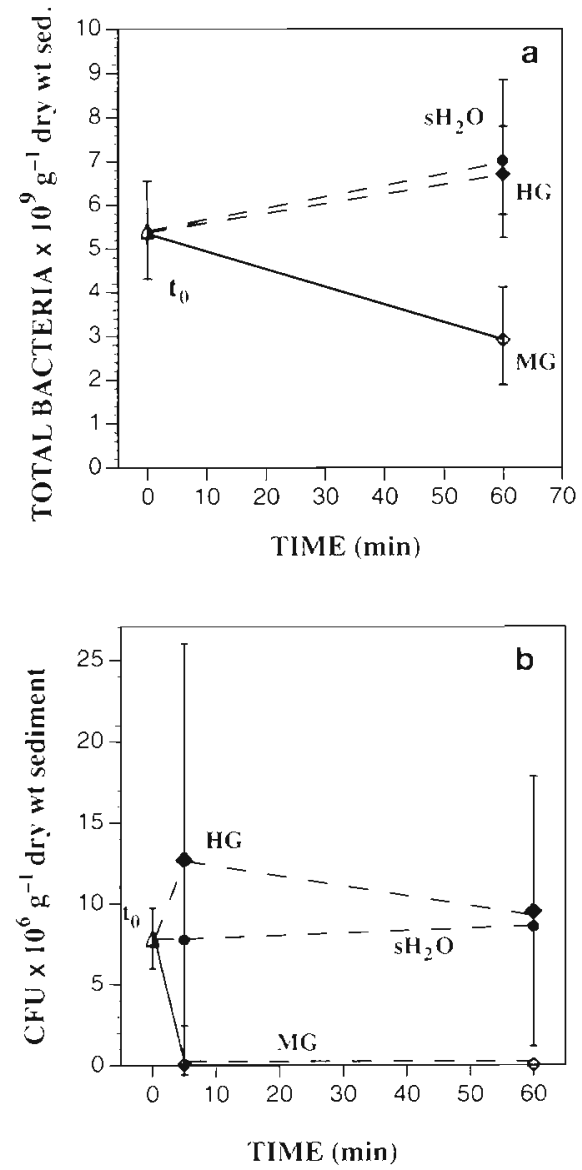

Fig. 5. Numerical trends of (a) total and (b) viable bacteria in surface sediments incubated with equal volumes of midgut fluids, hindgut fluids, or seawater. Solid lines connecting points indicate significantly different $(p<0.05)$ counts

but the evidence of secretory additions was somewhat less obvious.

The lytic activity in Amphitrite johnstoni was lower than that observed in Arenicola marina by roughly 50 to $70 \%$; it was, however, more evenly distributed through the gut. Although activity was observed in both Stereobalanus canadensis and Caudina arenata gut sections, neither of the other deposit feeders exhibited activities comparable to that of the polychaetes (Table 2). Again, activity appeared more evenly distributed than in A. marina but some concentration in the middle and posterior regions was apparent.

\section{DISCUSSION}

We normalized our lytic activities both to fluid weight and to weight of dry sediment. Our observations convinced us that bacteriolytic activity can be found in portions of the gut devoid of particulate mat- 
Table 2. Lytic activities [mean \pm 1 SD (n)] normalized to fluid and dry sediment weights of ingesta, along with fluid content (\%) for each gut region of 4 deposit feeders

\begin{tabular}{|c|c|c|c|}
\hline \multirow[t]{2}{*}{ Gut section } & \multicolumn{2}{|c|}{ Lytic activity } & \multirow[t]{2}{*}{ Wet wt. $(\%)$} \\
\hline & $\Delta \mathrm{A}_{450} \mathrm{~min}^{-1}$ wet $\mathrm{g}^{-1}$ & $\Delta \mathrm{A}_{450} \mathrm{~min}^{-1} \mathrm{dry} \mathrm{g}^{-1}$ & \\
\hline \multicolumn{4}{|l|}{ Arenicola marina } \\
\hline Esophagus & $0.4 \pm 0.9$ & $0.8 \pm 1.2$ & $21.5 \pm 3.5$ \\
\hline Ceca & $22.9 \pm 16.8$ & - & $99.6 \pm 0.7$ \\
\hline Anterior stomach & $42.7 \pm 31.2(6)$ & $44.0 \pm 25.6$ & $62.1 \pm 28.2$ \\
\hline Posterior stomach & $29.3 \pm 28.4$ & $14.1 \pm 5.8 \quad$ (7) & $51.8 \pm 27.8$ \\
\hline Anterior intestine & $0.7 \pm 1.0$ & $0.2 \pm 0.3$ & $25.3 \pm 6.8$ \\
\hline Posterior intestine & $0.1 \pm 0.2$ & $0.4 \pm 0.8$ & $25.8 \pm 7.6$ \\
\hline Anterior rectum & $0.2 \pm 0.2$ & $0.1 \pm 0.1$ & $29.3 \pm 3.7$ \\
\hline Posterior rectum & $0.1 \pm 0.2$ & $0.1 \pm 0.1$ & $26.8 \pm 6.1$ \\
\hline \multicolumn{4}{|l|}{ Amphitrite johnstoni } \\
\hline Esophagus & $1.6 \pm 1.3$ & $0.3 \pm 0.5$ & $67.2 \pm 19.1$ \\
\hline Anterior stomach & $8.2 \pm 3.4$ & $33.4 \pm 16.4$ & $81.0 \pm 12.2$ \\
\hline Posterior stomach & $10.9 \pm 1.1$ & $29.8 \pm 12.7$ & $70.0 \pm 15.2$ \\
\hline Anterior intestine & $11.6 \pm 3.0$ & $21.8 \pm 6.2$ & $69.0 \pm 9.1$ \\
\hline Posterior intestine & $6.0 \pm 2.0$ & $11.7 \pm 0.5$ & $66.5 \pm 6.4$ \\
\hline \multicolumn{4}{|l|}{ Caudina arenata } \\
\hline Esophagus & $0.25 \pm 0.44$ & $0.60 \pm 1.20$ & $72.6 \pm 1.9$ \\
\hline Anterior intestine-1 & $3.78 \pm 6.44$ & $30.67 \pm 52.82(3)$ & $78.0 \pm 7.5$ \\
\hline Anterior intestine-2 & $1.07 \pm 2.03$ & $2.10 \pm 3.90$ & $69.3 \pm 6.8$ \\
\hline Posterior intestine & $0.57 \pm 0.78$ & $1.30 \pm 1.80$ & $71.8 \pm 3.9$ \\
\hline Cloaca & $0.15 \pm 0.18$ & $0.50 \pm 0.60$ & $75.7 \pm 6.2$ \\
\hline \multicolumn{4}{|l|}{ Stereobalanus canadensis } \\
\hline Anterior intestine-1 & $0.30 \pm 0.51$ & $1.59 \pm 2.75$ & $81.0 \pm 3.6$ \\
\hline Anterior intestine-2 & $3.69 \pm 6.78$ & $19.34 \pm 36.93(5)$ & $82.3 \pm 1.4$ \\
\hline Anterior intestine-3 & $3.19 \pm 3.20$ & $13.03 \pm 13.24(5)$ & $80.6 \pm 3.7$ \\
\hline Posterior intestine & $3.71 \pm 2.47$ & $17.50 \pm 14.69(5)$ & $81.4 \pm 5.1$ \\
\hline
\end{tabular}

ter; we therefore regard as more significant the lytic values normalized to fluid weight, although trends for both are similar. Fluid-weight normalization gives an idea of the concentration of lytic agents in the fluids, a mixture of animal secretions and sediment porewater, to which ingested bacteria are exposed. Within a species, lytic activity was not correlated with amount of ingesta; gut sections nearly devoid of solid ingesta demonstrated lytic capabilities comparable to those regions filled with sediment. A high value of lytic activity normalized to dry weight, then, is more an indication of an empty gut than lytic strength. Dry-weight normalizations do, however, reveal the extent to which ingesta are bathed by digestive secretions in animals like Arenicola marina, in which changes in fluid content are obvious.

Bacteriolytic activity, expressed in terms of either dry sediment or fluid weight, in the gut of Arenicola marina is concentrated in the midgut. This observation supports our predictions based on cost-benefit models (Plante et al. 1990), and agrees with observed longitudinal patterns of bacterial numbers in various depositfeeder guts le.g. Deming \& Colwell 1982, Duchene et al. 1988, Plante et al. 1989). Digestive enzymes in $A$. marina are similarly distributed with proteases, carbohydrases and esterase/lipases largely confined to the ceca and stomach (Longbottom 1970, Mayer unpubl.). The ceca are indicated as the source of lytic agent as their contents exhibit strong lytic activity and visually resemble stomach contents in color and soapiness. That the stomach showed a still higher (although not significantly so) lytic capacity may implicate the stomach as an additional source of lytic agents.

New insights regarding the mechanisms of bacteriolysis are revealed in the present study. Filtered gut fluids added to sediments caused lysis, as did the supernatants of centrifuged extracts, suggesting that particulates are unimportant and intracellular digestion (e.g. by amoebocytes) of bacteria in the gut lumen is unlikely. Preliminary observations suggest that the lytic agent is not lysozyme as anticipated and likely is not an enzyme at all. Contrary to the results of Grossman \& Reichardt (1991), who used whole Arenicola marina guts extracted in Tris- $\mathrm{HCl}$ buffer versus the phosphate-buffer-extracted gut contents employed in this study, we observed very little lysis of the Gram- 
positive bacterium Micrococcus lysodeikticus, but rapid lysis of the Gram-negative SS-1. Further tests with 3 more Gram-negative and 2 more Gram-positive isolates resulted in similar trends (Plante unpubl.). Because enzymes often are associated with the cells of the gut wall (e.g. Feral 1989), the disparate results of Grossman \& Reichardt (1991) and those of the present study may not be surprising. We made numerous efforts to replicate their results using whole-gut homogenates in Tris- $\mathrm{HCl}$ buffer, however, and were unable to obtain appreciable lysis of $M$. Iysodeikticus. The complete explanation for this discrepancy is unclear at this time; closer examination of the data, however, reveals that our results are less contradictory than first appearances would suggest. Although not reported in their manuscript, their initial bacterial densities were approximately $3 \times 10^{8} \mathrm{ml}^{-1}$ (S. Grossman pers. comm.); these data combined with their rate data (their Fig. 6) reveal that the lytic rates that they observed for $M$. lysodeikticus (maximal values of $\sim 3 \%$ $\mathrm{min}^{-1}$ ) were much lower than what we observed for SS-1 (maximal values $>70 \% \mathrm{~min}^{-1}$ ) and more comparable to our controls. The difference, then, may be that they were able to achieve non-lytic controls whereas our phosphate buffer or Tris- $\mathrm{HCl}$ controls always showed some small amount of lysis, roughly equal to what we observed in $M$. lysodeikticus resuspensions with added gut fluids. $M$. lysodeikticus is highly susceptible to lysozyme (and is used in standardized lysozyme assays) as are many Gram-positive bacteria, whereas Gram-negative bacteria are typically much more resistant. Additionally, preliminary experiments show that ca $90 \%$ of the lytic rate of SS-1 exposed to gut fluids is retained after these fluids are microwaved or boiled, indicating a non-enzymatic source of lysis, and further investigations have revealed high levels of surfactants in the gut which appear to correlate with lytic activity (Plante unpubl.). A surfactant lysing agent is also consistent with the observed greater susceptibilty of Gram-negative bacteria (e.g. Varra 1992, Johnson 1994). Although certain products of digestion, e.g. various fatty acids and peptides, can exhibit surfactant activity, the observation of bacteriolysis in the particlefree (Kermack 1955, Plante pers. obs.), and presumably food-free, ceca points to an actively secreted lytic agent.

Little activity was measured in the esophagus, indicating an absence of axial mixing of digestive secretions. In most cases bacteriolytic activity was much reduced or even negligible in all other portions of the gut, surface sediments, and fecal coils relative to the midgut. This observation allows the calculation that exposure time to the lytic portion of the gut on the dates of collection is approximately $20 \mathrm{~min}$; this estimate is fairly rough, however, since relative lengths of gut sections were used as surrogote measures for gut volume. The diameter of the alimentary tract of Arenicola marina clearly is not constant from mouth to anus (e.g. Fig. 1); the stomach is generally wider but so too is the stomach less tightly packed with ingested materials and more filled with secretory fluids. In addition, our method of estimating mean gut residence time assumes that the weight of sediment in the gut upon dissection is similar to gut-sediment weight at defecation. The calculations of Kermack (1955), in which the weight of sediment in one defecation event exceeded the weight of sediment in the entire gut of $A$. marina, illustrate that a gross misrepresentation of residence time will result if gut fullness does vary. Given our observations that egestion rate remained constant up to 30 min after emersion, we are confident that assumptions regarding gut fullness were met.

The disappearance or inactivation of the lytic agent posterior to the stomach cannot be explained with conviction at this time. The apparent removal of fluids in posterior regions of the gut, especially apparent in Arenicola marina, however, may suggest the recycling of digestive secretions. Given the low quality of food ingested by deposit feeders, a strategy for efficient recycling seems especially appropriate, particularly in those animals which secrete relatively large quantities of digestive agents and exhibit short gut residence times. One function of the peritrophic membrane, found in the Terebellidae and other polychaetes (Dales \& Pell 1970), may be to enable absorption and redistribution of secretions, potentially by a mechanism similar to that demonstrated in dipteran larvae (EspinozaFuentes \& Terra 1987). One alternate hypothesis is that a countercurrent flow retains fluids within the midgut, resulting in a longer midgut residence time for liquids relative to the sediment plug. Such a scenario runs counter to predictions based on optimal digestion theory that deposit feeders should function as plug-flow reactors with negligible axial mixing of reactants (Penry \& Jumars 1987). Plug-flow of sediment particles for some deposit feeders has been demonstrated (Penry 1989 Plante unpubl.); the absence of axial mixing in the liquid phase, however, remains undocumented.

Our experiments in which undiluted gut fluids were mixed with bacterial resuspensions in seawater demonstrate that gut fluids near their natural dilutions are sufficient to lyse bacterial cells under normal osmotic conditions. Although the addition of gut fluids enhanced the lysis of SS-1 over the lysis due to potassium phosphate buffer, resuspension in phosphate buffer alone caused some lysis and stimulated lysis in the presence of gut fluids relative to a seawater resuspension. Resuspension in phosphate buffer increased the sensitivity of the assay procedure, which proved 
useful given the small amounts of fluids encountered in some gut sections coupled with the dilutions necessary to extract these fluids from ingested sediments. The probable mechanism of enhanced lysis in the presence of phosphate buffer is osmotic disruption (Stolp \& Starr 1965), although interference with stabilizing divalent cations $\left(\mathrm{Ca}^{2+}\right.$ and $\left.\mathrm{Mg}^{2+}\right)$ on the lipopolysaccharide-covered cell surfaces (Varra 1992) could also contribute to greater lytic susceptibility. These same experiments demonstrated with parallel viable and total counts that cell viability (or cultivability) was lost prior to lysis.

Experiments in which fresh surface sediments were incubated with gut fluids of Arenicola marina showed that, although in situ bacteria were lysed by midgut fluids, the efficiency of lysis was substantially lower than that for a cultured single strain. Prominent explanations among many possibilities for this disparity are exopolymer secretions, varying growth stages, and differential susceptibility among in situ bacteria. Exopolymer secretions have been shown to inhibit enzymatic digestion of microbes, although mechanisms for this protection are still uncertain (Decho 1990). Preliminary portions of the present study offer some evidence for the latter 2 suggestions: stationary-phase cells were shown to be less susceptible to lysis and marked differences to susceptibility were observed between Micrococcus lysodeikticus and SS-1. That log-phase bacteria are more susceptible to digestion than stationaryphase cells may have implications for the concept of gardening (Hylleberg 1975); macrofaunal activity may not only stimulate microbial biomass production, but also simultaneously increase the microbes' susceptibility to digestion.

The experiments in which sediments were incubated with gut fluids also corroborated the idea that cell inactivation is more widespread than cell lysis, with viable counts decreasing much more than total counts. Although we suspect that bacteria in these experiments were killed, we conservatively use the term 'inactivation' to acknowledge the possibility that only cultivability on 2216 agar was lost due to some sublethal stress (e.g. Ray 1993). The estimated $20 \mathrm{~min}$ exposure time in the midgut of Arenicola marina appears to be sufficient to inactivate most ingested bacteria, based on the reductions seen after only $5 \mathrm{~min}$ in the inoculated surface sediments, especially since these fluids were diluted to approximately $50 \%$ of concentrations in the gut. On the contrary, direct microscopic examination reveals that the cellular integrity of more than half of the natural microbiota associated with these sediments persists.

The importance of bacteria to the diet of deposit feeders remains an open issue. In the present study, the qualitative change in DAPI-stained cells upon exposure to midgut fluid likely is due to a loss of cell wall integrity and DNA leakage. A strategy to lyse and release intracellular components of ingested bacteria rather than merely inactivating them is suggested. This finding would seem to agree with numerous reports of numerical losses of tatal bacteria through the gut of deposit feeders (e.g. Deming \& Colwell 1982, Duchene et al. 1988, Plante et al. 1989, Grossman \& Reichardt 1991). The qualitative change in staining intensity, however, will clearly make visualization of gut samples more difficult and resulting counts more subjective - hence, more prone to error (especially underestimation). Although deposit feeders can grow on a diet of bacteria alone (e.g. Zobell \& Feltham 1938) and radioisotope studies have shown that bacterial carbon is efficiently absorbed by deposit feeders (Kofoed et al. 1989, Lopez et al. 1989 and references within), generally it is believed that bacteria contribute a rather minor portion to the deposit-feeder diet. Numerous studies suggest that sedimentary bacteria contribute less than $10 \%$ of the required carbon of deposit feeders (e.g. Kemp 1987, 1990, Plante et al. 1989). The focus on carbon versus nitrogen or energy, however, may have tended to underestimate the relative contributions of bacteria (Tenore et al. 1982, Jumars et al. 1990). Less controversial, but also less frequently addressed, is the role of ingested bacteria as competitors. Based on relative absorptive areas, competition with bacteria for soluble digestive products should be significant in an animal the size of Arenicola marina (with gut diameters often exceeding $5 \mathrm{~mm}$ ); lysis of ingested bacteria would therefore appear to be a necessary competitive strategy (Plante et al. 1990). Thus, there may be a dual function for the lytic agents in $A$. marina: competitive removal of bacteria and nutritive gain.

Cross-phyletic comparisons of bacteriolytic capacity suggest fundamentally diverse digestive approaches. To maximize food gain per unit time, various strategies are possible, and are probably heavily dependent on the chemical nature of the food resource. The polychaetes in our study inundate the ingesta with concentrated digestive fluids. The time for which ingesta are exposed to these fluids, however, is relatively short; less than $1 \mathrm{~h}$ for Arenicola marina (Kermack 1955, present study). On the other hand, bacteriolytic activity in the guts of Caudina arenata and Stereobalanus canadensis is much weaker, and the gut fluids visually appear to contain smaller proportions of animal secretions. The relatively constant fluid content of ingesta throughout the gut of these animals, versus the widely fluctuating levels in A. marina, corroborates this idea. Enzymatic assays (for protease, carbohydrase and esterase) show parallel results in that the same polychaete species used in this study exhibit relatively high activities whereas apodous holothuroids and other 
echinoderms demonstrate much reduced activities (Mayer unpubl.). A positive correlation between activity levels and visual characteristics (pigment and soapiness) was also observed in these enzyme studies. Unfortunately, we did not obtain gut residence times for any of the other 3 animals in our study. Literature values for sediment-feeding holothuroids, however, suggest much longer residence times, from 2 to $36 \mathrm{~h}$ (Feral 1989, Penry 1989). Our prediction would be that $S$. canadensis and other hemichordates have similarly long gut residence times. The strategy of the polychaetes in this study may be to specialize on an easily digested fraction of the sediment with rapid renewal, whereas $C$. arenata and $S$. canadensis might concentrate on a slower but more thorough removal of a greater fraction of substrate with a consequently longer gut residence time. Our inability to address this question stems directly from the extreme difficulty in identifying the nutritional resources of deposit feeders.

Acknowledgements. We thank C. Giray, S. Schnell, L. Schick, and $A$. Laursen for assistance with laboratory and field portions of this project. We are indebted to Dr Gary King for helpful discussions and use of his facilities. Financial support was provided by NSF grant OCE 92-03063. Contribution \#272 from the Darling Marine Center

\section{LITERATURE CITED}

Aller, R. C., Yingst, J. Y. (1985). Effects of the marine deposit feeders Heteromastus filiformis (Polychaeta), Macoma balthica (Bivalvia), and Tellina texana (Bivalvia) on averaged sedimentary solute transport, reaction rates, and microbial distributions. J. mar. Res. 43: 615-645

Austin, D. A., Baker, H. J. (1988). Fate of bacteria ingested by larvae of the freshwater Mayfly Ephemera danica. Microb. Ecol. 15: 323-332

Azam, F., Fenchel, T., Field, J. G., Gray, J. S., Meyer-Reil, L. A., Thingstad, F. (1983). The ecological role of watercolumn microbes in the sea. Mar. Ecol. Prog. Ser. 10: $257-263$

Baker, J. H., Bradnam, L. A. (1976). The role of bacteria in the nutrition of aquatic detritivores. Oecologia 24: 94-105

Dade, W. B., Jumars, P. A., Penry, D. L. (1989). Supply-side optimization: maximizing absorptive rates. In: Hughes, R. N. (ed.) Behavioral mechanisms of food selection. Springer-Verlag, New York, p. 531-556

Dales, R. P., Pell, J. S. (1970). The nature of the peritrophic membrane in the gut of the terebellid polychaete Neoamphitrite figulus. Comp. Biochem. Physiol. 34: 819-826

Decho, A. W. (1990). Microbial exopolymer secretions in ocean environments: their role(s) in food webs and marine processes. Oceanogr. mar. Biol. A. Rev. 28: 73-153

Deibel, D., Powell, C. V. L. (1987). Ultrastructure of the pharyngeal filter of the appendicularian Oikopleura vanhoeffeni: implications for particle size selection and fluid mechanics. Mar. Ecol. Prog. Ser. 35: 243-250

Deming, J. W. Colwell, R. R. (1982). Barophilic growth of bacteria from intestinal tracts of deep-sea invertebrates. Microb. Ecol. 7: 85-94

Dobbs, F. C.. Guckert, J. B. (1988). Microbial food resources of the macrofaunal-deposit feeder Ptychodera bahamensis
(Hemichordata: Enteropneusta). Mar. Ecol. Prog. Ser. 45 $127-136$

Duchene, J. C., Imbaud, P., Delille, D. (1988). Associated bacterial microflora of a subantarctic polychaete worm Thelepus setosus. Arch. Hydrobiol. 112: 221-231

Dye, A. H. (1983). A method for the quantitative estimation of bacteria from mangrove sediments. Estuar coast. Shelf Sci. 17: 207-212

Ellery, W. N., Schleyer, M. H. (1984). Comparison of homogenization and ultrasonication as techniques in extracting attached sedimentary bacteria. Mar. Ecol. Prog. Ser. 15: $247-250$

Espinoza-Fuentes, F. P., Terra, W. R. (1987). Physiological adaptations for digesting bacteria. Water fluxes and distribution of digestive enzymes in Musca domestica larval midgut. Insect Biochem. 17: 809-817

Fenchel, T. (1972). Aspects of decomposer food chains in marine benthos. Verh. dtsch. zool. Ges. 14: 14-22

Feral, J.-P. (1989). Activity of the principal digestive enzymes in the detritivorous apodous holothuroid Leptosynapta galliennei and two other shallow-water holothuroids. Mar. Biol. 101: $367-379$

Grossmann, S., Reichardt, W. (1991). Impact of Arenicola marina on bacteria in intertidal sediments. Mar. Ecol. Prog. Ser. 77: 85-93

Hargrave, B. T (1970). The effect of a deposit-feeding amphipod on the metabolism of benthic microflora. Limnol. Oceanogr. 15: 21-30

Hylleberg, J. (1975). Selective feeding by Abarenicola pacifica with notes on Abarenicola vagabunda and a concept of gardening in lugworms. Ophelia 14: 113-137

Johnson, J. L. (1994). Similarity analysis of DNAs. In: Gerhardt, P., Murray, R. G. E., Wood, W. A., Krieg, N. R. (eds.), Methods for general and molecular bacteriology. Am. Soc. Microbiol., Washington, DC, p. 655-682

Jumars, P. A., Mayer, L. M., Deming, J. W., Baross, J. A., Wheatcroft, R. A. (1990). Deep-sea deposit-feeding strategies suggested by environmental and feeding constraints. Phil. Trans. R. Soc. Lond. A 331. 85-101

Juniper, S. K. (1981). Stimulation of bacterial activity by a deposit feeder in two New Zealand intertidal inlets. Bull. mar. Sci, 31: 691-701

Kemp, P. F. (1987). Potential impact on bacteria of grazing by a marine deposit feeder, and the fate of bacterial production. Mar. Ecol. Prog. Ser. 36: 151-161

Kemp, P. F. (1990). The fate of benthic bacterial production. Rev. Aquat. Sci. 2: 109-24

Kermack, D. M. (1955). The anatomy and physiology of the gut of the polychaete Arenicola marina L. Proc. Zool. Soc. Lond. 125: 347-381

Klug, M. J., Kotarski, S. (1980). Ecology of the microbiota in the posterior hindgut of larval stages of the crane fly Tipula abdominalis. Appl. environ. Microbiol. 40: 408-416

Kofoed, L., Forbes, V., Lopez, G. (1989). Time-dependent absorption in deposit feeders. In: Lopez, G. R., Taghon, G. L., Levinton, J. S. (eds.) The ecology of marine deposit feeders. Springer-Verlag, New York, p. 129-148

Leifson, E. (1963). Determination of carbohydrate metabolism of marine bacteria. J. Bacteriol. 85: 1183-1184

Longbottom, M. R. (1970). Distributions of the digestive enzymes in the gut of Arenicola marina. J. mar. biol. Ass. U.K. 50: $121-128$

Lopez, G., Tantichodok, P., Cheng, I-J. (1989). Radiotracer methods for determining utilization of sedimentary organic matter by deposit feeders. In: Lopez, G. R., Taghon, G. L., Levinton, J. S. (eds.) The ecology of marine deposit feeders. Springer-Verlag, New York, p. 149-170 
McHenery, J. G., Birkbeck, T H. (1982). Characterization of the lysozyme of Mytilus edulis (L.). Comp. Biochem. Physiol. 71B: $583-589$

Moriarty, D. J. W., Pollard, P. C., Hunt, W. G., Moriarty, C. M., Wassenberg, T. J. (1985). Productivity of bacteria and microalgae and the effect of grazing by holothurians in sediments on a coral reef flat. Mar. Biol. 85: 293-300

Morsky, P. (1983). Turbidimetric determination of lysozyme with Micrococcus lysodeikticus cells: re-examination of reaction conditions. Anal. Biochem. 128: 77-85

Newell, R.C. (1965). The role of detritus in the nutrition of two marine deposit feeders, the prosobranch Hydrobia ulvae and the bivalve Macoma balthica. Proc. Zool. Soc. Lond. 144: $25-45$

Penry, D. L. (1989). Tests of kinematic models for deposit feeders' guts: patterns of sediment processing by Parastichopus californicus (Stimpson) (Holothuroidea) and Amphicteis scaphobranchiata Moore (Polychaeta). J. exp. mar. Biol. Ecol. 128: 127-146

Penry, D. L., Jumars, P. A. (1986). Chemical reactor analysis and optimal digestion. BioSci. 36: 310-315

Penry, D. L., Jumars, P. A. (1987). Modeling animal guts a chemical reactors. Am. Nat. 129:69-96

Plante, C. J., Jumars, P. A. (1993). Immunofluorescence assay for effects on abundance of a naturally occurring pseudomonad during passage through the gut of a marine deposit feeder, Abarenicola pacifica. Microb. Ecol. 26: 247-266

Plante, C. J., Jumars, P. A., Baross, J. A. (1989). Rapid bacterial growth in the hindgut of a marine deposit feeder. Microb. Ecol. 18: 29-44

Plante, C. J., Jumars, P. A., Baross, J. A. (1990). Digestive associations between marine detritivores and bacteria. A. Rev. Ecol. Syst. 21: 93-127

This article was submitted to the editor
Pomeroy, L. R., Hanson, R. B., McGillivary, P. A., Sherr, B. F., Kirchman, D., Deibel, D. (1984). Microbiology and chemistry of fecal products of pelagic tunicates: rates and fates. Bull. mar. Sci. 35: 426-439

Prieur, D., Mevel, G., Nicolas, J.-L., Plusquellec, A., Vigneulle, M. (1990). Interactions between bivalve molluscs and bacteria in the marine environment. Oceanogr. mar. Biol. A. Rev. 28: 277-352

Ray, B. (1993). Sublethal injury, bacteriocins, and food microbiology. ASM News 59: 285-291

Reyes, V. G., Tiedje, J. M. (1976). Ecology of gut microbiota of Tracheoniscus rathkei (Crustacea, Isopoda). Pedobiologia 16: $67-74$

Stolp, H., Starr, M. P. (1965). Bacteriolysis. A. Rev. Microbiol. 19: $79-104$

Taghon, G. L. (1988). The benefits and costs of deposit feeding in the polychaete Abarenicola pacifica. Limnol. Oceanogr. 33: 1166-1175

Tenore, K., Cammen, L., Finlay, S., Phillips, N. (1982). Perspectives in factors controlling detritus mineralization depending on detritus source. J. mar. Res. 40:473-490

Varra, M. (1992). Agents that increase the permeability of the outer membrane. Microbiol. Rev. 56: 395-411

Wavre, M., Brinkhurst, R. O. (1971). Interactions between some tubificid oligochaetes and bacteria found in the sediments of Toronto Harbour, Ontario. J. Fish, Res. Bd Can. 28: $335-341$

Wheatcroft, R. A., Jumars, P. A., Smith, C. R., Nowell, A. R. M. (1990). A mechanistic view of the particulate biodiffusion coefficient: step lengths, rest periods and transport directions. J. mar. Res. 48: 177-207

Zobell, C. E., Feltham, C. B. (1938). Bacteria as food for certain marine invertebrates. J. mar. Res. 1: 312-327

Manuscript first received: September 1, 1993

Revised version accepted: March 31, 1994 